\section{Chronic organ injuries in children with sickle cell disease}

\author{
Slimane Allali, ${ }^{1,2,3}$ Melissa Taylor, ${ }^{1,3,4}$ Joséphine Brice ${ }^{1,3,5}$ and Mariane de \\ Montalembert ${ }^{1,3,5}$
}

${ }^{1}$ Department of General Pediatrics and Pediatric Infectious Diseases, Reference Center for Sickle Cell Disease, Necker Hospital for Sick Children, Assistance Publique - Hôpitaux de Paris (AP-HP), Université de Paris, Paris; 'Laboratory of Cellular and Molecular Mechanisms of Hematological Disorders and Therapeutical Implications, Université de Paris, Imagine Institute, Inserm U1163, Paris; ${ }^{3}$ Laboratory of Excellence GR-Ex, Paris; ${ }^{4}$ Paris-Cardiovascular Research Centre (PARCC), Université de Paris, Inserm U970, Paris and ${ }^{5}$ Institut National de la Transfusion Sanguine (INTS), Université de Paris, Inserm U1134, Paris, France

\section{ABSTRACT}

M edian life expectancy of patients with sickle cell disease has increased to up to 55 years but there are still frequent cases of premature death, mostly in patients with pre-existing organ failure such as pulmonary hypertension, kidney injury, and cerebral vasculopathy. Most organ injuries remain asymptomatic for a long time and can only be detected through early systematic screening. Protocols combining assessment of velocities on transcranial Doppler and regular transfusions in patients with abnormal velocities have been demonstrated to dramatically reduce the risk of stroke. In contrast, no consensus has been reached on systematic screening or therapy for silent cerebral infarcts. The prognostic significance of increased tricuspid regurgitant jet velocity on echocardiography has not yet been identified in children, whereas increased albuminuria is a good predictor of kidney injury. Finally, screening for hip and eye disorder is recommended; however, different countries adopt different screening strategies. Hydroxyurea is probably of potential benefit in preventing chronic organ damage but this requires further study in order to be fully demonstrated. Efficacy and safety of the other new drugs available are also under investigation.

\section{Introduction}

In high-income countries, $>98 \%$ of children affected by sickle cell disease (SCD) reach adulthood, and the disease has shifted from being a fatal illness in children to a chronic disease with multiple organ dysfunction in adults. ${ }^{1.4}$ Median life expectancy has increased to up to approximately 55 years, ${ }^{4 \cdot 8}$ which remains far below the life expectancy of ethnicity-matched non-SCD controls. ${ }^{4}$ Fatalities mostly occur in patients with pre-existing organ failure, such as kidney injury, cerebral vasculopathy, and pulmonary hypertension. ${ }^{7.8}$ Most organ injuries remain asymptomatic for several decades and can only be detected through early systematic screening. Identification of early predictors of organ damage could help guide the initiation of specific treatments for the injured organ, prevent secondary worsening, and optimize SCD management. To date, increased velocities on transcranial Doppler in children and elevated tricuspid regurgitant jet velocity in adults are the only validated predictors of risk of stroke and death, respectively., ${ }^{9,10}$ Biological predictors of severity are mostly limited to hemolysis markers, and have weak individual predictive values. ${ }^{5,11-15}$ There is still no genetic signature of severity robust enough to predict individual outcome. ${ }^{16}$ Thus, regular screening for early signs of organ dysfunction appears to be the best strategy for the prevention of secondary organ failure and early mortality. In this review, we describe the main chronic organ dysfunctions reported in children with SCD and propose a checklist of screening tests.

\section{Pathophysiology of chronic organ injury}

SCD originates from the sickle mutation on the $H B B$ gene (Glu6Val, $\beta S$ ), the most common and severe form being homozygous HbSS. Other forms of SCD
Ferrata Storti Foundation

Haematologica 2021

Volume 106(6):1535-1544

\section{Correspondence:}

MARIANE DE MONTALEMBERT

mariane.demonta@@nck.aphp.fr

Received: September 25, 2020.

Accepted: November 6, 2020.

Pre-published: February 25, 2021.

https://doi.org/10.3324/haematol.2020.271353

(C2021 Ferrata Storti Foundation

Material published in Haematologica is covered by copyright. All rights are reserved to the Ferrata Storti Foundation. Use of published material is allowed under the following terms and conditions:

https://creativecommons.org/licenses/by-nc/4.0/legalcode. Copies of published material are allowed for personal or internal use. Sharing published material for non-commercial purposes is subject to the following conditions:

https://creativecommons.org/licenses/by-nc/4.0/legalcode, sect. 3. Reproducing and sharing published material for commercial purposes is not allowed without permission in writing from the publisher. 
include compound heterozygous conditions, such as hemoglobin $\mathrm{C}(\mathrm{HbC})$ with $\mathrm{HbS}(\mathrm{HbSC}), \mathrm{HbS}$ with $\beta$-thalassemia ( $\mathrm{HbS} / \beta^{0}$-thalassemia or $\mathrm{HbS} / \beta^{+}$-thalassemia), and $\mathrm{HbS}$ with other $\beta$-globin variants resulting in sufficient $\mathrm{HbS}$ expression to cause sickling. Under deoxygenation, sickle hemoglobin ( $\mathrm{HbS})$ polymerizes and erythrocytes undergo a rapid but reversible change in shape, resulting in both chronic hemolysis and small-vessel obstruction, which have long been recognized as the main contributors to SCD pathophysiology. ${ }^{17}$ Paradoxically, tissue injury is exacerbated by reperfusionenabled re-entry of oxygen during the ischemia/reperfusion process (I/R). I/R is responsible for systemic inflammation, hypercoagulability, and endothelial dysfunction via various mechanisms. ${ }^{18}$ Endothelial vasoregulatory dysfunction is observed from childhood, ${ }^{19,20}$ and chronic anemia is responsible for concomitant increased blood flow. The association of macrovascular hyperemia and microvascular hypoperfusion, that Hebbel et al. referred to as the sickle cell "perfusion paradox", is extremely challenging for major organs such as the brain, kidney, and heart, which may fail to respond and adapt to the need for increased oxygen. ${ }^{18}$ Moreover, systemic inflammation is amplified by the release of free heme and hemoglobin during hemolysis, inducing oxidative stress, cell death, and vascular integrity damage. ${ }^{21}$ Heme was notably shown to be a potent activator of endothelial cells, leading to an increased expression of major adhesion molecules such as P-selectin. ${ }^{21}$ Finally, each organ (and, indeed, each patient) represents a unique combination of hypoxia, inflammatory and oxidative stress, activation of innate immunity, hyperviscosity and hypercoagulability in response to genetic and environmental agedependent drivers. Organ defense may be adapted for a certain length of time, or 'over-adapted', for example, when neoangiogenesis induces the generation of a network of collateral vessels which are prone to ruptures, provoking ocular or cerebral hemorrhages. Sickling-related acute events may be regressive with unsickling but endothelial damage is most often irreversible.

Chronic organ injuries will be presented here according to their impact on mortality in adult patients.

\section{Cardiovascular abnormalities}

Main cardiovascular disorders in SCD are pulmonary hypertension (PHT) and left ventricular dysfunction. These are the main contributors to SCD-related mortality in adults, accounting for $>30 \%$ of all deaths among SCD patients in the US. ${ }^{22}$ They are more frequent and severe in patients with $\mathrm{HbSS}$ or $\mathrm{HbS} / \boldsymbol{\beta}^{0}$-thalassemia. ${ }^{23,24}$

\section{Pulmonary hypertension}

In addition to the pathophysiology common to all organ injuries described above, increased cardiac output resulting from chronic anemia is a risk factor for PHT in SCD. Hypoxia induces smooth muscle cell and intimal proliferation, and in situ thrombosis can increase pulmonary vascular resistance. These factors contribute to the development of PHT and right heart enlargement, which ultimately leads to right heart failure. In addition, post-capillary PHT is promoted by diastolic dysfunction, which may be related to myocardial fibrosis. In children, however, PHT seems to be mostly related to increased cardiac output while pulmonary vascular resistance remains normal. ${ }^{25}$

Historically, PHT in adults and children was defined as a mean pulmonary artery pressure (mPAP) $\geq 25 \mathrm{mmHg}$ but the current threshold proposed by the $6^{\text {th }}$ World Symposium on Pulmonary Hypertension is $>20 \mathrm{mmHg}{ }^{26}$ Prevalence in adults with SCD ranges from 10\% to $33 \%$ when measured by right heart catheterization (RHC) or echocardiography, respectively. ${ }^{24}$ Pulmonary artery systolic pressure (PASP) is assessed on echocardiography by the quantification of the tricuspid regurgitant jet velocity (TRV) using the modified Bernoulli equation. Raised TRV was shown to be a risk factor for death in adults..$^{10,27,28}$ However, the positive predictive value of TRV for diagnosing PHT in adults remains controversial. No study has assessed the correlation between TRV and RHC in SCD children. Given the risk of RHC procedure in this patient population, it is only recommended when TRV is $>3 \mathrm{~m} / \mathrm{s}$ and is only to be carried out in experienced pediatric centers. ${ }^{26}$ In a meta-analysis using a threshold of TRV $\geq 2.5$ $\mathrm{m} / \mathrm{s}, 21 \%$ (95\% CI: $17-26 \%$ ) of children and adolescents were considered to have elevated PASP, which was positively associated with age. ${ }^{29}$ Nevertheless, TRV $\geq 2.5 \mathrm{~m} / \mathrm{s}$ may be observed as early as three years of age in SCD children. ${ }^{30}$ Several studies have shown the influence of hemolysis on the occurrence of PHT in children. ${ }^{31-34}$ Hemoglobin oxygen desaturation is frequently reported in SCD children, especially at night and after exercise, but its association with elevated TRV is more controversial. . $^{31,34}$

In contrast with adults, increased TRV in SCD children has not so far been associated with increased mortality in adulthood. In a cross-sectional study of 483 adolescents and adults with SCD, raised TRV was associated with poor exercise capacity. ${ }^{35}$ Furthermore, one study of 160 HbSS patients aged 3-20 years showed that baseline elevation in TRV was associated with a 4.4-fold increase in the odds of a $10 \%$ or more decline in age-standardized 6 minute-walk distance over a median of 22 months. ${ }^{32}$ Importantly, evaluation of PHT should not be based on a single assessment of TRV, as demonstrated in a follow-up cohort of 120 children with SCD, in which an improvement in TRV values was observed over a period of $15 \pm 9$ months in half of the patients, although there was no clear explanation for this. ${ }^{36}$

\section{Screening and prevention}

US recommendations suggest performing an echocardiography when symptoms are suggestive of PHT, whereas many European experts recommend measuring TRV once a year in children, usually after five years of age. ${ }^{37,38}$ In cases of elevated TRV, the cardiopulmonary risk should be evaluated by a full workup including electrocardiography (ECG), chest radiography, functional respiratory tests with 6-minute-walk distance measurement, cardiopulmonary exercise test, overnight oxygen saturation monitoring, polysomnography for obstructive sleep apnea, and measurement of brain natriuretic peptide (BNP) and N-terminal pro-BNP levels. TRV $\geq 2.5 \mathrm{~m} / \mathrm{s}$ should suggest the need to optimize SCD treatment, although prospective controlled studies have not demonstrated the benefits of hydroxyurea and chronic transfusion on PHT. Retrospective data suggest either improvement of PHT with hydroxyurea ${ }^{39}$ or no effect of the drug. ${ }^{31,33}$ 


\section{Left ventricular diastolic dysfunction}

SCD patients usually exhibit left ventricular (LV) dilation, closely correlated to the severity of anemia. Over time, progressive dilation leads to increased wall stress, increased LV mass, and impaired LV filling, which is associated with increased mortality in SCD adults. ${ }^{23,40}$ Diastolic dysfunction is linked to microscopic myocardial fibrosis in transgenic SCD mice, and to diffuse myocardial fibrosis on cardiac magnetic resonance imaging (MRI) in patients. ${ }^{40,41}$

\section{Myocardial ischemia}

Myocardial ischemia in SCD patients appears to be related to microvascular perfusion defect rather than to coronary artery occlusion. ${ }^{42} \mathrm{~A}$ few cases of acute myocardial ischemia or subclinical myocardial injuries have been reported in children with SCD. ${ }^{42,43}$ In a series of 22 SCD children with chest pain, or ECG or echocardiographic signs (LV dilation or hypokinesis) who underwent single photon emission computed tomography, myocardial hypoperfusion was found in eight of them. Perfusion defects were more frequent in older children. In this study, myocardial perfusion was reassessed in three patients after 6 months of hydroxyurea and was found to be improved. ${ }^{43}$

\section{Cardiac iron overload}

The heart does not appear to be an early target for iron deposition in chronically transfused SCD patients, and this is particularly the case in young patients. ${ }^{44,45}$ In a multicentric study of regularly transfused SCD patients either on manual exchange transfusion $(n=30)$ or erythrocytapheresis $(n=11)$, none had cardiovascular MRI values of T2* $<20 \mathrm{~ms}$, in spite of high median ferritin levels $(2,700$ and $2,400 \mathrm{ng} / \mathrm{mL}$ for manual exchange and erythrocytapheresis procedures, respectively) and liver iron content (10 and $14 \mathrm{mg} / \mathrm{g}$ dry weight for manual exchange and erythrocytapheresis procedures, respectively). ${ }^{44}$ The rarity of cardiac iron overload may partly be explained by the fact that, in SCD, iron is efficiently recycled by erythropoiesis or trapped within macrophages because of chronic inflammation. ${ }^{44}$

\section{Lung disease}

Respiratory complications were found to be the second cause of death (at 28\%) in adults with SCD in the US between 1999 and 2009. ${ }^{22}$ Chronic complications in SCD include chronic dyspnea, reduced exercise capacity, and loss of lung function. Abnormalities in lung function have frequently been reported in children with SCD, although results remain a subject of debate, both regarding the frequency of these abnormalities and the predominant restrictive or obstructive pattern. ${ }^{46-48} \mathrm{~A}$ review of 149 children aged 6-19 years, of whom 139 were followed prospectively for a median of 4.3 years, found normal, obstructive, restrictive, non-specific, and mixed baseline lung function patterns in $70 \%, 16 \%, 7 \%, 6 \%$, and $1 \%$ of patients, respectively. ${ }^{49}$ Baseline lung function patterns were not associated with pain or acute chest syndrome rate either before the pulmonary function tests or during follow-up. In contrast, another study found that occurrence of acute chest syndrome was associated with a greater decline in lung function..$^{50}$ In a prospective study of
146 patients with $\mathrm{HbSS}$ or $\mathrm{HbS} / \beta^{0}$ thalassemia, normal, obstructive, restrictive, and non-specific lung function patterns were observed in $61 \%, 19 \%, 9 \%$, and $11 \%$ of patients, respectively. ${ }^{51}$ Older age, patient or family history of asthma or wheezing, and higher lactate dehydrogenase levels were independent predictors of obstruction. One study reported that $96.5 \%$ of patients had normal lung function at eight years of age, but the authors observed a longitudinal decline in lung volumes through adolescence, with a restrictive pattern in 19\% of patients by the age of $17 .{ }^{52}$ Discrepancies between studies may be due to the different thresholds used for defining patterns and to the small numbers of patients, most often analyzed retrospectively in cross-sectional studies. Lung function may also vary depending on geographical area, with a higher reported prevalence of restrictive patterns in patients from sub-Saharan Africa compared to those from high-income countries. ${ }^{48}$ Overall, obstruction seems to predominate in children whereas restriction is more common in adults. ${ }^{53}$ Asthma has been found to be associated with acute chest syndrome occurrence and pain ${ }^{54}$ but its effect on lung function growth is not clear. ${ }^{55}$ Unresolved issues include the question as to whether there is a link between abnormal lung function and relevant outcomes such as progressive dyspnea, pulmonary hypertension, and early mortality. ${ }^{49}$

\section{Screening and prevention}

The question of systematically screening all SCD children with pulmonary function tests remains a subject of debate. ${ }^{37,38,55}$ Proponents argue that identifying an undiagnosed obstructive pattern may help to prevent acute asthma crises and therefore reduce the risk of acute chest syndrome.

\section{Kidney disease}

Renal complications in SCD include hyposthenuria, glomerular hyperfiltration, glomerulosclerosis, albuminuria, and end-stage renal disease. These are responsible for approximately $14-16 \%$ of mortality in adults with SCD in the US and are more frequent in patients with HbSS and $\mathrm{HbS} / \beta^{0}$-thalassemia. ${ }^{56}$ In addition to the pathophysiological processes previously described in SCD organ injuries, kidney injury is enhanced by the particularly hypoxic, acidic, and hypertonic environment of the renal medulla which induces red blood cell sickling in the vasa recta, with ischemia and infarction of the tubular cells. The kidney is a very good example of the "perfusion paradox" in SCD, with the association of macrovascular whole-kidney hyperhemia, and microvascular medullary blood flow hypoperfusion. In young patients, elevated cardiac output leads to increased renal blood flow, glomerular hypertrophy, and increased glomerular filtration rate (GFR), the latter being observed as early as childhood. ${ }^{57}$ GFR then decreases with age, especially in patients developing kidney disease. In addition to hyperperfusion, there is a decrease in vascular resistance, which might be related to heme-driven heme oxygenase- 1 induction and the release of vasorelaxants such as prostaglandins. ${ }^{56} \mathrm{I} / \mathrm{R}$ injuries and heme release seem to play a major role in the development of acute kidney injury (AKI) and chronic kidney disease (CKD) via oxidative stress, apoptosis induction, and activation of the complement system. ${ }^{58,59}$ 
Renal manifestations vary greatly depending on the patient and his or her age. Hyposthenuria is observed from infancy in the majority of children. Enuresia is very frequent and may have a severe psychological impact. Hyperfiltration occurs very early, as evidenced by 99 -technetium diethylenetriaminepentaacetate (DTPA) plasma clearance measurements in infants with SCD aged 9-19 months enrolled in the BABY HUG trial..$^{57}$ Baseline DTPA glomerular filtration rate (GFR) was $125 \pm 34 \mathrm{~mL} / \mathrm{min} / 1.73$ $\mathrm{m}^{2}$ (range: $40-300 \mathrm{~mL} / \mathrm{min} / 1.73 \mathrm{~m}^{2}$ ) compared with the published normal value of $91 \pm 18 \mathrm{~mL} / \mathrm{min} / 1.73 \mathrm{~m}^{2}(10-$ $90 \%$ range: $60-120 \mathrm{~mL} / \mathrm{min} / 1.73 \mathrm{~m}^{2}$ ) for this age group. ${ }^{57}$ On average, baseline DTPA GFR increased by 3 $\mathrm{mL} / \mathrm{min} / 1.73 \mathrm{~m}^{2}$ for every one month increase in age. ${ }^{57}$ Hyperfiltration, defined as estimated GFR (eGFR) $>180$ $\mathrm{mL} / \mathrm{min} / 1.73 \mathrm{~m}^{2}$, was also evidenced using cystatin $\mathrm{C}$ measurement in a cohort of 91 children with HbSS and $\mathrm{HbS} / \beta^{0}$-thalassemia aged $5-21$ years. ${ }^{60}$ Thirty-nine patients $(43 \%)$ had hyperfiltration and nine of them (23\%) progressed to microalbuminuria, defined as albumin to creatinine ratio $30-300 \mathrm{mg} / \mathrm{g}$, compared with three of the 52 patients $(6 \%)$ without hyperfiltration. Several studies have demonstrated that hyperfiltration increases during early childhood, remains stable before adolescence, then decreases as progressive CKD continues. ${ }^{60-62}$ eGFR $<90$ $\mathrm{mL} / \mathrm{min} / 1.73 \mathrm{~m}^{2}$ is seen in $8-21 \%$ of adolescents. ${ }^{61-63}$ Albuminuria may develop in some children. In a series of 410 SCD patients aged 2-21 years, microalbuminuria was found in $21 \%$ ( $70 \%$ of them were $\mathrm{HbSS}$ and $\mathrm{HbS} / \beta^{\circ}$-thalassemics); macroalbuminuria (defined as albumin to creatinine ratio $\geq 300 \mathrm{mg} / \mathrm{g}$ creatinine) was presented in three $\mathrm{HbSS}$ patients. In $\mathrm{HbSS}$ and $\mathrm{HbS} / \boldsymbol{\beta}^{0}$-thalassemics, abnormal albuminuria was associated with older age and lower baseline hemoglobin level. ${ }^{61}$

SCD patients with CKD may have a stable renal function but are at risk of AKI during vaso-occlusive crisis or other concomitant illness. ${ }^{64}$ In a retrospective study, AKI was found in $17 \%$ of 197 admissions for vaso-occlusive pain. ${ }^{64}$ At admission, every 'one unit' drop in hemoglobin levels compared to patients' baseline values increased the risk of AKI by $49 \%$. Ketorolac administration (in terms of total days and doses) was also associated with AKI but the role of non-steroidal anti-inflammatory drugs (NSAID) could not be formally confirmed because of the retrospective nature of the study. The impact of the decrease in hemoglobin levels on the occurrence of AKI compared to baseline values has also been observed in children during acute chest syndrome, ${ }^{65}$ and may reflect a direct toxic effect of free heme or hemoglobin released during hemolysis on the kidney.

Renal dysfunction is more severe and frequent in patients with $\mathrm{HbSS}$ and $\mathrm{HbS} / \beta^{0}$-thalassemia, and is associated with anemia. ${ }^{66}$ As in other diseases, nocturnal hypertension and hyperuricemia have been associated with lower eGFR. ${ }^{67}$ The predictive value of an APOL1 genetic profile has recently been suggested for onset of renal disease in children with SCD. ${ }^{68}$

\section{Screening and prevention}

Screening for kidney disease should not be based on serum creatinine level in children with SCD because of increased eGFR, often lower muscle mass, and increased tubular secretion of creatinine. ${ }^{61}$ Albuminuria is a good predictor of risk for $\mathrm{CKD}$ and can be used for routine screening. The National Heart Lung and Blood Institute recommends screening for albuminuria starting at ten years of age for all SCD patients. ${ }^{68}$ The gold standard for measuring GFR is inulin clearance but this is costly. Therefore, cystatin $\mathrm{C}$ and creatinine-based estimations of GFR (Schwartz equation using patient height and creatinine value) may be more relevant for annual screening..$^{60}$ In children, it must be remembered that a normal GFR is an alarm signal as it should, in fact, be elevated in the context of initial hyperfiltration.

Hydroxyurea may be considered in patients with elevated microalbuminuria but the results of existing studies are controversial. Hydroxyurea was not superior to placebo in the prevention of hyperfiltration in the BABY-HUG trial, although it was associated with a better concentrating ability and less renal enlargement. ${ }^{69,70}$ In pediatric series, hydroxyurea was associated with a trend for a decrease in the frequency of microalbuminuria ${ }^{71-73}$ and with a significant decrease in DTPA GFR in 23 children with a median age of 7.5 years. $^{74}$

Very few studies have reported the use of angiotensin converting enzyme inhibitors (ACE I), combined or not with hydroxyurea, in SCD children with albuminuria. ${ }^{71,75}$ Albuminuria decreased in some children treated with ACE I but some patients experienced hyperkalemia, prompting interruption of ACE I therapy.

\section{Cerebrovascular disease}

Patients affected with SCD may suffer from ischemic and hemorrhagic stroke, silent cerebral infarction, and neurological decline. Cerebrovascular events account for approximately $12 \%$ of SCD-related mortality in the US. ${ }^{22}$ In children, these represent the third cause of death after infections and hematologic complications (acute splenic sequestration and other causes of acute anemia). ${ }^{76}$ Furthermore, cerebrovascular events are responsible for a high rate of motor and cognitive disabilities. ${ }^{77}$ The brain provides a good illustration of the "perfusion paradox" of SCD, combining hyperperfusion within the arteries of the circle of Willis and microvascular hypoperfusion. Hemolysis and $I / R$ injuries generate inflammation, endothelial dysfunction, and intimal hyperplasia. The roles of hemodynamic changes and procoagulant status are still under investigation. ${ }^{18,77}$

Cerebral vasculopathy mostly affects $\mathrm{HbSS}$ and $\mathrm{HbS} / \beta^{0}$ thalassemia patients. Events may be overt or so-called 'silent', which is an inappropriate term since silent cerebral infarcts (SCI) were found to be associated with cognitive defects. $^{78}$ Overt events are mostly ischemic, occurring with two peaks of frequency either before the age of ten or after 40 years of age, but may also be hemorrhagic with an increasing incidence associated with age. Risk factors include a lower steady-state $\mathrm{Hb}$ level, prior transient ischemic attack, recent or frequent acute chest syndromes, high systolic blood pressure, ${ }^{11}$ nocturnal hypoxemia, ${ }^{79}$ a past history of bacterial meningitis, ${ }^{11}$ and the presence of silent infarcts on MRI. ${ }^{80}$ The role of co-existent G6PD deficiency is controversial, as it was found to increase the risk of stroke in one,$^{81}$ but not all, studies. ${ }^{82}$ Increased HbF level and presence of $\alpha$-thalassemia may have a protective effect. ${ }^{81}$ Hemorrhagic strokes may complicate moya-moya syndromes or may be related to ruptured aneurysm, the prevalence of which is increased in SCD patients, most likely due to the effect of flow disturbances on the vascular wall. ${ }^{77}$ 
SCI are the most common neurological events in SCD children, occurring in approximately one-third of patients before the age of 14 years; there is no plateau with increasing age. ${ }^{83}$ Reported risk factors for SCI include male gender, lower baseline hemoglobin concentrations, higher baseline systolic blood pressure, and previous seizures. $^{78}$

\section{Screening and prevention}

The brain is probably the only organ for which preventive strategies have shown efficacy in SCD patients. Transcranial Doppler (TCD) measures the flow velocity in the large intracranial arteries of the circle of Willis where stenosis or flow turbulences may induce a local acceleration. Children may be stratified as being at low, intermediate, or high risk of stroke according to normal, conditional, or abnormal velocities, respectively. ${ }^{9}$ Adams et al. showed that children with time-averaged mean velocity (TAMV) measured in the distal internal carotid artery or middle cerebral artery $\geq 200 \mathrm{~cm} / \mathrm{s}$ had a 6 -fold higher risk of stroke than children with normal TCD velocities (TAMV $<170 \mathrm{~cm} / \mathrm{s}$ ). ${ }^{9}$ For these high-risk patients, initiation of monthly blood transfusion reduced the risk of stroke by $90 \% .{ }^{84}$ Alternatively, hydroxyurea has been used for primary and secondary stroke prevention in low-resource settings. ${ }^{85}$ Cerebral vasculopathy revealed by abnormal TCD is an indication for hematopoietic stem cell transplant in children with HLAidentical sibling. When velocities are normal, the current recommendation in children with $\mathrm{HbSS}$ and $\mathrm{HbS} / \beta^{\circ}$-thalassemia is annual TCD screening from 2 to $\geq 16$ years. ${ }^{37}$ Conditional TCD is an intermediate category that warrants performing $\mathrm{MRI} /$ magnetic resonance angiography (MRA) and controlling TCD, as conversion to abnormal TCD may occur. ${ }^{86}$ Many teams consider conditional velocities as an indication for hydroxyurea treatment. ${ }^{38}$ Very low blood-flow velocities $(<70 \mathrm{~cm} / \mathrm{s})$ suggest poststenotic demodulation or near-occlusive arterial disease. ${ }^{87}$ Finally, elevated velocities $(>160 \mathrm{~cm} / \mathrm{s})$ in the extracranial part of the internal carotid artery are also associated with increased risk of stroke, notably in patients who are free of intracranial arterial vasculopathy; ${ }^{38,89}$ however, there is still no clear recommendation on which treatment strategy to use. Our personal recommendation is to use the same strategy for both intra- and extra-cranial abnormalities. TCD may detect blood flow alterations before occurrence of MRI/MRA abnormalities allowing for early management at a stage when it might be possible to prevent the situation worsening. ${ }^{90}$ MRI/MRA is recommended in children with conditional TCD findings and in children with incomplete TCD assessment, usually due to a lack of a bone window or to an underlying arterial occlusion. In 2014, a panel of experts did not recommend systematic MRI in asymptomatic children with $\mathrm{HbSS}$ and $\mathrm{HbS} / \beta^{0}$-thalassemia. ${ }^{37}$ However, brain MRI can reveal aneurysms or SCI, which are associated with decreased cognitive ability, and these might benefit from hydroxyurea treatment. Therefore, some centers recommend performing brain MRI in SCD children at least once. ${ }^{91}$ Our personal experience is to recommend systematic MRI at around six years of age (an age at which it is expected that most children would have already started school) since early diagnosis of SCI usually leads to a more thorough evaluation of academic ability and performance with implementation of educational and psychological support when required. Management of SCI is still nonconsensual. Hydroxyurea has been suggested to reduce their extension or recurrence..$^{22}$ Use of chronic transfusion is a subject of debate as this therapy has only moderate efficacy on the progression of SCI. ${ }^{91}$

\section{Liver disease}

The main acute manifestations of liver disease in SCD include sickle cell hepatic crisis, sickle cell intrahepatic cholestasis, and hepatic sequestration, while chronic manifestations include cholelithiasis, sickle cell cholangiopathy, auto-immune hepatitis, viral hepatitis, and iron overload..$^{3}$ The prevalence of liver disease in adults with SCD is estimated to be approximately $10 \% .^{93}$ In a cohort of 3,500 adult patients, liver failure was considered to be the cause of death in $7 \%$ of cases. ${ }^{8}$ Hepatobiliary complications are more rarely reported in children with SCD, most probably because they are not routinely screened for and are thus under-diagnosed. ${ }^{94}$

The pathophysiology of these complications is mostly related to the sickling of red blood cells, resulting in sinusoidal obstruction and ischemia of hepatocytes, as well as ischemia of bile ducts leading to cholangiopathy. Hemolysis-related hyperbilirubinemia promotes biliary lithiasis. Liver damage in SCD may also be due to iron overload, viral infection, or autoimmune disorders, the frequency of which is increased in SCD patients compared to the general population..$^{95}$

A retrospective review of 616 SCD children followedup in a reference center for both SCD and hepatology found that $37 \%$ had presented at least one hepatobiliary complication. ${ }^{94}$ Among chronic complications, gallstones were diagnosed in $25 \%$ of children, cholangiopathy in $0.8 \%$, autoimmune hepatitis in $0.5 \%$, transfusion iron overload in $3 \%$, and iron chelator toxicity was suspected in $0.8 \%$. Over half of the gallstones were discovered incidentally, although complications occurred in $42 \%$ of cases, mostly occurring as pain, as well as cholecystitis, cholangitis, and pancreatitis. Among acute complications, the combined prevalence of acute sickle cell crisis, sickle cell intrahepatic cholestasis, and acute hepatic sequestration was approximately $6 \% .{ }^{94}$ Post-transfusion iron overload is usually asymptomatic in children but may have severe consequences in adults..$^{93}$

\section{Screening and prevention}

In order to prevent gallstone-related complications, we recommend abdominal ultrasonography once a year after the age of five years, and elective cholecystectomy in case of gallstone even in asymptomatic patients, although there is currently no consensus for this preventive strategy. ${ }^{37,96}$ Liver injury can be screened by performing twiceyearly liver tests (mainly alanine aminotransferase [ALT] and conjugated bilirubin). ${ }^{94}$ In patients with dilated bile ducts, MR-cholangiography should be performed and hypergammaglobulinemia should also be screened for as autoantibodies for autoimmune liver disease. Liver MRI should be performed every year in children aged $>5$ years undergoing a monthly transfusion program in order to assess liver iron content. Iron chelation is recommended in case of iron overload but adhesion to chelator therapy is often low. ${ }^{44}$ Lastly, anti-hepatitis B immunization is mandatory. 


\section{Ophthalmic disease}

Patients affected with SCD are at risk of retinopathy, which may result in sight-threatening complications, such as vitreous hemorrhage and retinal detachment. Ocular manifestations of SCD differ from previously described complications as peripheral retinopathy is more frequent in patients with HbSC than in patients with $\mathrm{HbSS} .{ }^{97,98} \mathrm{The}$ reasons for this finding are not fully understood although the blood hyperviscosity commonly observed in $\mathrm{HbSC}$ patients (who display higher hemoglobin levels than HbSS patients) could contribute to retinal ischemia. On the other hand, it has been hypothesized that increased vascular endothelial growth factor (VEGF) and angiopoietin production in response to chronic anemia could play a role by promoting angiogenesis. ${ }^{99}$

The prevalence of retinopathy has been estimated at $24 \%$ in $\mathrm{HbSS}$ and $\mathrm{HbS} / \beta^{\circ}$ adult patients versus $61 \%$ in $\mathrm{HbSC}$ and $\mathrm{HbS} / \beta^{+}$patients. ${ }^{97}$ Non-proliferative retinopathy includes salmon-patch hemorrhages, iridescent spots, black sunbursts, and arteriovenous anastomoses. Patients are usually asymptomatic as long as the retinopathy is non-proliferative but secondary development of neovascularization, presenting as sea fans, bears the risk of vision loss due to vitreous hemorrhage or retinal detachment. A retrospective review of 263 children with SCD found proliferative retinopathy in seven cases $(2.7 \%)$, including six with $\mathrm{HbSC}$ (occurring at a median age of 13.7 years; range: 9-18), one with HbSS (occurring at 16 years of age), and none with $\mathrm{HbS} / \beta$-thalassemia. ${ }^{98}$ More recently, a high prevalence of temporal macular retinal atrophy diagnosed by optical coherence tomography (OCT) has been reported in SCD patients, including children, which may have direct consequences on visual function with impaired color vision ability and contrast sensitivity, even when visual acuity is preserved ${ }^{100}$ In a retrospective series of 81 children (mean age 12 years; standard deviation [SD]: 3.5 years) with SCD (64 HbSS, $7 \mathrm{HbS} / \beta^{0}$-thalassemia, 10 $\mathrm{HbSC}$ ), temporal macular retinal atrophy was observed in $64 \%$ of cases with no significant difference in prevalence between HbSS and HbSC genotype. ${ }^{101}$ In this series, peripheral retinopathy was observed in $11 \%$ of patients and was more severe in children with HbSC.

Recent multimodal MRI evaluation of the visual cortex in 25 SCD children (mean age: 12.3 years; SD: 1.9 years) compared to 31 controls, found increased posterior pericalcarine cortical thickness, with different trajectory of cortical maturation and decreased connectivity within visual neural networks. ${ }^{102}$ Whether these changes may represent useful predictors of visual impairment in adulthood needs to be assessed by further studies.

\section{Screening and prevention}

There is universal consensus on the recommendation that children with SCD should be screened regularly for retinopathy with a dilated fundoscopic examination, starting earlier in children with HbSC than in children with $\mathrm{HbSS}$ genotypes. ${ }^{37,38,98}$ Nine and 13 years of age have been proposed as appropriate time points to start systematic controls in HbSC and HbSS children, respectively. ${ }^{97}$ However, since temporal macular retinal atrophy seems to occur early in the course of SCD, especially for patients with $\mathrm{HbSS},{ }^{100}$ we personally recommend annual controls, including OCT, starting at six years of age. A simple annual survey is recommended for children with non-proliferative retinopathy and laser photocoagulation is generally proposed to children with severe proliferative retinopathy.

\section{Hip abnormalities}

Osteonecrosis of the femoral head (ONFH) is the main osteoarticular complication of SCD with an estimated prevalence ranging from $10 \%$ to $30 \%$ in adults. ${ }^{103}$ This relatively high frequency may be explained by several factors. Firstly, vascularization of superior femoral epiphysis depends on the retinacular vessels, which originate from branches of the medial circumflex arteries in a terminal vascularization model, with limited possibilities of reperfusion when these vessels are occluded by sickling red blood cells. In addition, the balance between osteoblastogenesis and osteoclastogenesis is most likely modified in patients with SCD during hypoxia-reperfusion cycles. ${ }^{104}$ Lastly, vitamin D deficiency is frequent in patients with SCD and may contribute to bone fragility. ${ }^{105}$

In a study of 2,590 SCD children and adults followed-up in the 1980 s for an average of 6 years, $10 \%$ of patients had ONFH at study inclusion. ${ }^{106}$ The prevalence of ONFH for patients aged 5-9 years, 10-14 years, and 15-24 years was $1.3 \%, 4.6 \%$, and $8.2 \%$, respectively. At follow-up, children with HbSS and $\alpha$-thalassemia were at the greatest risk for osteonecrosis. The frequency of painful crises, age, and hematocrit were positively associated with osteonecrosis. ${ }^{106}$ The influence of hydroxyurea on the incidence of OFNH is much debated, although the interpretation of most studies is limited by the fact that they are cross-sectional and retrospective, including only a limited number of patients. ${ }^{103}$

\section{Screening and prevention}

It has been shown that early treatment of ONFH, either conservative or operative, can lead to good functional outcomes with $75 \%$ of congruent hips at skeletal maturity. ${ }^{107}$ Early diagnosis is therefore mandatory. There is agreement on the need to investigate all children with SCD presenting intermittent or chronic hip pain for avascular necrosis by means of a full history and physical examination, X-ray, and MRI, as needed. Advice from an orthopedic department should be requested. ${ }^{37}$ At a pre-collapse stage, ONFH is, however, asymptomatic, and this observation has led a French panel of experts to recommend systematic hip X-ray after the age of 6 years with a checkup every 1-3 years. ${ }^{38}$

\section{Conclusion}

The median life expectancy of patients with SCD has increased to up to 55 years, which can be considered a significant achievement with regard to the natural history of the disease. ${ }^{3}$ However, detection and management of chronic organ failure still need to be improved in order to reach the life expectancy of the general population without major disabilities. Detecting and preventing early organ injury would not only reduce early mortality but may also improve quality of life. There is still no consensus on the best strategies for detecting and preventing chronic organ dysfunction in SCD patients. For these reasons, we propose a summary of the main recommendations from both a US and a European panel of experts on SCD in Table 1..$^{37,108}$ 
Apart from stroke prevention, the quality of evidence regarding the efficacy of actual screening strategies is still not high enough. Moreover, the ability of chronic transfusion, hydroxyurea and other drugs to prevent chronic organ failure has not been demonstrated by controlled studies. However, several encouraging studies do suggest a potential benefit of hydroxyurea to prevent degradation of renal function. The impact of new drugs such as crizanluzimab and voxelotor on organ function is still under investigation. While there are still no individual predictive factors, current strategy options may be to propose hydroxyurea to all $\mathrm{HbSS}$ and $\mathrm{HbS} / \beta^{\circ}$ children; this option has been considered by US and British experts. ${ }^{37}$ Another option may be to take the view that the potential severity of SCD in adults justifies proposing hematopoietic stem cell transplantation (and, in the future, gene therapy) even in asymptomatic patients. This debate is still ongoing, but it will be essential that patients help define their own health priorities and play a role in the design of clinical research.

Table 1. Screening tools in children and adolescents for the detection of chronic organ complications of sickle cell disease.

\begin{tabular}{|c|c|c|c|c|}
\hline Organ & $\begin{array}{l}\text { Sereening tool } \\
\text { (apart from history and } \\
\text { physical examination) }\end{array}$ & $\begin{array}{l}\text { US } \\
\text { recommendations } \\
\text { for screening }\end{array}$ & $\begin{array}{l}\text { Recommendations from a } \\
\text { European panel of experts } \\
\text { for screening }\end{array}$ & Evidence-basec \\
\hline \multicolumn{5}{|l|}{ Heart } \\
\hline Pulmonary hypertension & TRV on echocardiography & $\begin{array}{l}\text { In case of symptoms } \\
\text { or suggestive signs }\end{array}$ & $\begin{array}{l}\text { Yearly } \\
\text { Systematic in all children }>5 \text { years }\end{array}$ & $\begin{array}{l}\text { No EBT } \\
\text { HU suggested }\end{array}$ \\
\hline Myocardial ischemia & ECG & $\begin{array}{l}\text { In case of symptoms } \\
\text { or suggestive signs }\end{array}$ & $\begin{array}{l}\text { In case of symptoms or } \\
\text { suggestive signs } \\
\text { Consider cardiac MRI }\end{array}$ & $\begin{array}{l}\text { No EBT } \\
\text { HU suggested }\end{array}$ \\
\hline
\end{tabular}

\begin{tabular}{|c|c|c|c|c|}
\hline \multicolumn{5}{|l|}{ Lung and airways } \\
\hline Pulmonary disease & Pulmonary function tests & In case of symptoms & $\begin{array}{l}\text { Yearly } \\
\text { Systematic in all children }>5 \text { years }\end{array}$ & $\begin{array}{l}\text { Anti-asthmatic treatments } \\
\text { if necessary }\end{array}$ \\
\hline Upper airway obstruction & $\begin{array}{l}\text { ENT control } \\
\text { (+ polysomnography when } \\
\text { necessary) }\end{array}$ & Yearly & Yearly & $\begin{array}{l}\text { Adeno-/tonsillectomy if upper } \\
\text { airway obstruction }\end{array}$ \\
\hline
\end{tabular}

\section{Kidney}

Renal failure Blood pressure

Creatinine, albuminuria

Systematic screening

Yearly systematic screening
No EBT

HU suggested if microalbuminuria ACE inhibitor suggested if proteinuria

Monthly transfusion in patients with velocities $>200 \mathrm{~cm} / \mathrm{s}$ age 2 to at least 16 years in SCA patients

No systematic MRI in asymptomatic children

Neurocognitive screenin Cerebral MRI
Yearly screening from age 2 to at least 16 years in SCA patients

No consensus Systematic MRI starting at 6 years old for some experts
No EBT

HU suggested if silent infarct
Liver

Cholangiopathy

Liver tests

Abdominal ultrasonography

Transfusion iron overload Ferritin

Liver iron content on

hepatic MRI
Systematic screening in chronically transfused patients Abdominal ultrasonography once
a year from age 5

Systematic screening in chronically transfused patients
No consensus

Elective cholecystectomy even in asymptomatic patients for some experts

Iron chelation

\begin{tabular}{lll}
$\begin{array}{ll}\text { Eye } \\
\text { Retinopathy }\end{array}$ & $\begin{array}{l}\text { Dilated fundoscopic } \\
\text { examination } \\
\text { OCT }\end{array}$ & No consensus \\
\hline $\begin{array}{l}\text { Hip } \\
\text { Osteonecrosis } \\
\text { of the femoral head }\end{array}$ & $\begin{array}{l}\text { Radiography } \\
\text { MRI }\end{array}$ & $\begin{array}{l}\text { In case of symptoms } \\
\text { (hip pain) }\end{array}$
\end{tabular}

Yearly examination after 10 years old (6 years old for some experts)

Laser photocoagulation if severe proliferative retinopathy

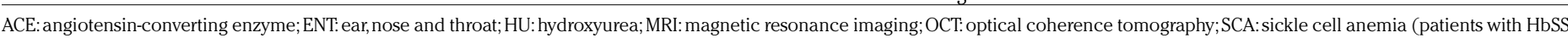
and $\mathrm{HbS} / \beta^{0}$-thalassemia genotypes); TRV: tricuspid regurgitant jet velocity. 
Disclosures

No conflicts of interest to disclose.

\section{Contributions}

$M M$ wrote the first draft of the manuscript; $S A, M T$ and JB assisted in writing the manuscript.

\section{References}

1. Quinn CT, Rogers ZR, McCavit TL, Buchanan GR. Improved survival of children and adolescents with sickle cell disease. Blood. 2010;115(17):3447-3452.

2. Couque N, Girard D, Ducrocq R, et al. Improvement of medical care in a cohort of newborns with sickle-cell disease in North Paris: impact of national guidelines. $\mathrm{Br} \mathrm{J}$ Haematol. 2016;173(6):927-937.

3. DeBaun MR. Perspective: thinking beyond survival. Nature. 2014;515(7526):S16.

4. Lubeck D, Agodoa I, Bhakta N, et al. Estimated life expectancy and income of patients with sickle cell disease compared with those without sickle cell disease. JAMA Netw Open. 2019;2(11):e1915374.

5. Elmariah H, Garrett ME, De Castro LM, et al. Factors associated with survival in a contemporary adult sickle cell disease cohort. Am J Hematol. 2014;89(5):530-535.

6. Lanzkron S, Carroll CP, Haywood C Jr. Mortality rates and age at death from sickle cell disease: U.S., 1979-2005. Public Health Rep. 2013;128(2):110-116.

7. Chaturvedi S, Ghafuri DL, Jordan N, Kassim A, Rodeghier M, DeBaun MR. Clustering of end-organ disease and earlier mortality in adults with sickle cell disease: a retrospective-prospective cohort study. Am J Hematol. 2018;93(9):1153-1160.

8. Habibi A, Ngo S, Audureau E, et al. Causes of death in 198 sickle cell adult patients: old and new trends. Blood. 2019;134(Suppl 1):1031.

9. Adams R, McKie V, Nichols F, et al. The use of transcranial ultrasonography to predict stroke in sickle cell disease. N Engl J Med. 1992;326(9):605-610.

10. Gladwin MT, Sachdev V, Jison ML, et al. Pulmonary hypertension as a risk factor for death in patients with sickle cell disease. N Engl J Med. 2004;350(9):886-895.

11. Ohene-Frempong K, Weiner SJ, Sleeper LA, et al. Cerebrovascular accidents in sickle cell disease: rates and risk factors. Blood. 1998;91(1):288-294

12. Platt OS, Brambilla DJ, Rosse WF, et al. Mortality in sickle cell disease. Life expectancy and risk factors for early death. N Engl J Med. 1994;330(23):1639-1644.

13. Kato GJ, McGowan V, Machado RF, et al. Lactate dehydrogenase as a biomarker of hemolysis-associated nitric oxide resistance, priapism, leg ulceration, pulmonary hypertension, and death in patients with sickle cell disease. Blood. 2006;107(6):2279-2285

14. Nouraie M, Lee JS, Zhang Y, et al. The relationship between the severity of hemolysis, clinical manifestations and risk of death in 415 patients with sickle cell anemia in the US and Europe. Haematologica. 2013;98(3): 464-472.

15. Meier ER, Wright EC, Miller JL. Reticulocytosis and anemia are associated with an increased risk of death and stroke in the newborn cohort of the Cooperative Study of Sickle Cell Disease. Am J Hematol. 2014:89(9):904-906.

16. Habara A, Steinberg MH. Minireview: genetic basis of heterogeneity and severity in sickle cell disease. Exp Biol Med (Maywood). 2016;241(7):689-696.

17. Ware RE, de Montalembert M, Tshilolo L, Abboud MR. Sickle cell disease. Lancet. 2017:390(10091):311-323.

18. Hebbel RP, Belcher JD, Vercellotti GM. The multifaceted role of ischemia/reperfusion in sickle cell anemia. J Clin Invest. 2020;130 (3):1062-1072.

19. Gladwin MT, Schechter AN, Ognibene FP, et al. Divergent nitric oxide bioavailability in men and women with sickle cell disease. Circulation. 2003;107(2):271-278.

20. de Montalembert M, Aggoun Y, Niakate A, Szezepanski I, Bonnet D. Endothelial-dependent vasodilation is impaired in children with sickle cell disease. Haematologica. 2007;92(12):1709-1710.

21. Belcher JD, Chen C, Nguyen J, et al. Heme triggers TLR4 signaling leading to endothelial cell activation and vaso-occlusion in murine sickle cell disease. Blood. 2014;123 (3):377-390.

22. Hamideh D, Alvarez O. Sickle cell disease related mortality in the United States (19992009). Pediatr Blood Cancer. 2013;60(9): 1482-1486

23. Gladwin MT, Sachdev V. Cardiovascular abnormalities in sickle cell disease. J Am Coll Cardiol. 2012;59(13):1123-1133.

24. Wood KC, Gladwin MT, Straub AC. Sickle cell disease: at the crossroads of pulmonary hypertension and diastolic heart failure. Heart. 2020;106(8):562-568.

25. Chaudry RA, Cikes M, Karu $T$, et al. Paediatric sickle cell disease: pulmonary hypertension but normal vascular resistance. Arch Dis Child. 2011:96(2):131-136.

26. Rosenzweig EB, Abman SH, Adatia I, et al. Paediatric pulmonary arterial hypertension: updates on definition, classification, diagnostics and management. Eur Respir J. 2019;53(1):1801916.

27. Cabrita IZ, Mohammed A, Layton M, et al. The association between tricuspid regurgitation velocity and 5 -year survival in a North West London population of patients with sickle cell disease in the United Kingdom. Br J Haematol. 2013;162(3):400-408.

28. Gladwin MT, Barst RJ, Gibbs IS, et al. Risk factors for death in 632 patients with sickle cell disease in the United States and United Kingdom. PLoS One. 2014;9(7):e99489.

29. Caughey MC, Poole C, Ataga KI, Hinderliter AL. Estimated pulmonary artery systolic pressure and sickle cell disease: a metaanalysis and systematic review. $\mathrm{Br} \mathrm{J}$ Haematol. 2015;170(3):416-424.

30. Colombatti R, Maschietto N, Varotto E, et al. Pulmonary hypertension in sickle cell disease children under 10 years of age. $\mathrm{Br} \mathrm{J}$ Haematol. 2010:150(5):601-609.

31. Minniti CP, Sable C, Campbell A, et al. Elevated tricuspid regurgitant jet velocity in children and adolescents with sickle cell disease: association with hemolysis and hemoglobin oxygen desaturation. Haematologica. 2009:94(3):340-347.

32. Gordeuk VR, Minniti CP, Nouraie M, et al. Elevated tricuspid regurgitation velocity and decline in exercise capacity over 22 months of follow up in children and adolescents with sickle cell anemia. Haematologica.
2011;96(1):33-40

33. Ambrusko SJ, Gunawardena S, Sakara A, et al. Elevation of tricuspid regurgitant jet velocity, a marker for pulmonary hypertension in children with sickle cell disease. Pediatr Blood Cancer. 2006;47(7):907-913.

34. Campbell A, Minniti CP, Nouraie M, et al. Prospective evaluation of haemoglobin oxygen saturation at rest and after exercise in paediatric sickle cell disease patients. Br J Haematol. 2009:147(3):352-359.

35. Sachdev V, Kato GJ, Gibbs JS, et al. Echocardiographic markers of elevated pulmonary pressure and left ventricular diastolic dysfunction are associated with exercise intolerance in adults and adolescents with homozygous sickle cell anemia in the United States and United Kingdom. Circulation. 2011;124(13):1452-1460.

36. Hebson C, New T, Record E, et al. Elevated tricuspid regurgitant velocity as a marker for pulmonary hypertension in children with sickle cell disease: less prevalent and predictive than previously thought? J Pediatr Hematol Oncol. 2015;37(2):134-139.

37. Yawn BP, Buchanan GR, Afenyi-Annan AN, et al. Management of sickle cell disease: summary of the 2014 evidence-based report by expert panel members. JAMA. 2014;312(10):1033-1048.

38. de Montalembert M, Tshilolo L, Allali S. Sickle cell disease: a comprehensive program of care from birth. Hematology Am Soc Hematol Educ Program. 2019;2019(1):490495.

39. Pashankar FD, Carbonella J, Bazzy-Asaad A, Friedman A. Longitudinal follow up of elevated pulmonary artery pressures in children with sickle cell disease. Br J Haematol. 2009;144(5):736-741.

40. Alsaied T, Niss O, Powell AW, et al. Diastolic dysfunction is associated with exercise impairment in patients with sickle cell anemia. Pediatr Blood Cancer. 2018;65 (8): 227113

41. Niss O, Fleck R, Makue F, et al. Association between diffuse myocardial fibrosis and diastolic dysfunction in sickle cell anemia. Blood. 2017;130(2):205-213.

42. Pavlu J, Ahmed RE, O'Regan DP, Partridge J, Lefroy DC, Layton DM. Myocardial infarction in sickle-cell disease. Lancet. 2007;369(9557):246.

43. de Montalembert M, Maunoury C, Acar P, Brousse V, Sidi D, Lenoir G. Myocardial ischaemia in children with sickle cell disease. Arch Dis Child. 2004;89(4):359-362.

44. de Montalembert M, Ribeil JA, Brousse V, et al. Cardiac iron overload in chronically transfused patients with thalassemia, sickle cell anemia, or myelodysplastic syndrome. PLoS One. 2017;12(3):e0172147.

45. Badawy SM, Liem RI, Rigsby CK, Labotka RJ, DeFreitas RA, Thompson AA. Assessing cardiac and liver iron overload in chronically transfused patients with sickle cell disease. Br J Haematol. 2016;175(4):705-713.

46. Sylvester KP, Patey RA, Milligan P, et al. Pulmonary function abnormalities in children with sickle cell disease. Thorax. 2004:59(1):67-70

47. Tassel C, Arnaud C, Kulpa M, et al. Leukocytosis is a risk factor for lung function 
deterioration in children with sickle cell disease. Respir Med. 2011;105(5):788-795.

48. Arigliani M, Kitenge R, Castriotta L, et al. Lung function in children with sickle cell disease from Central Africa. Thorax. 2019;74(6):604-606.

49. Cohen RT, Strunk RC, Rodeghier M, et al. Pattern of lung function is not associated with prior or future morbidity in children with sickle cell anemia. Ann Am Thorac Soc. 2016;13(8):1314-1323.

50. Lunt A, McGhee E, Sylvester $\mathrm{K}$, et al. Longitudinal assessment of lung function in children with sickle cell disease. Pediatr Pulmonol. 2016;51(7):717-723.

51. Arteta M, Campbell A, Nouraie M, et al. Abnormal pulmonary function and associated risk factors in children and adolescents with sickle cell anemia. J Pediatr Hematol Oncol. 2014;36(3):185-189.

52. MacLean JE, Atenafu E, Kirby-Allen M, et al. Longitudinal decline in lung volume in a population of children with sickle cell disease. Am J Respir Crit Care Med. 2008;178 (10):1055-1059.

53. Koumbourlis AC. Lung function in sickle cell disease: an elusive relationship. Pediatr Pulmonol. 2016;51(7):665-667.

54. Boyd JH, Macklin EA, Strunk RC, DeBaun MR. Asthma is associated with acute chest syndrome and pain in children with sickle cell anemia. Blood. 2006;108(9):2923-2927.

55. Field JJ, DeBaun MR, Yan Y, Strunk RC. Growth of lung function in children with sickle cell anemia. Pediatr Pulmonol. 2008;43(11):1061-1066.

56. Nath KA, Hebbel RP. Sickle cell disease: renal manifestations and mechanisms. Nat Rev Nephrol. 2015;11(3):161-171.

57. Ware RE, Rees RC, Sarnaik SA, et al. Renal function in infants with sickle cell anemia: baseline data from the BABY HUG trial. J Pediatr. 2010;156(1):66-70

58. Merle NS, Grunenwald A, Rajaratnam H, et al. Intravascular hemolysis activates complement via cell-free heme and heme-loaded microvesicles. JCI Insight. 2018;3(12): e96910.

59. Van Avondt K, Nur E, Zeerleder S. Mechanisms of haemolysis-induced kidney injury. Nat Rev Nephrol. 2019;15(11):671692

60. Lebensburger JD, Aban I, Pernell B, et al. Hyperfiltration during early childhood precedes albuminuria in pediatric sickle cell nephropathy. Am J Hematol. 2019;94(4): 417-423.

61. McPherson Yee M, Jabbar SF, Osunkwo I, et al. Chronic kidney disease and albuminuria in children with sickle cell disease. Clin J Am Soc Nephrol. 2011;6(11):2628-2633.

62. Aygun B, Mortier NA, Smeltzer MP, Hankins JS, Ware RE. Glomerular hyperfiltration and albuminuria in children with sickle cell anemia. Pediatr Nephrol. 2011;26(8):1285-1290.

63. Bodas P, Huang A, O'Riordan MA, Sedor JR, Dell KM. The prevalence of hypertension and abnormal kidney function in children with sickle cell disease - a cross sectional review. BMC Nephrol. 2013;14:237.

64. Baddam S, Aban I, Hilliard L, Howard T, Askenazi D, Lebensburger JD. Acute kidney injury during a pediatric sickle cell vasoocclusive pain crisis. Pediatr Nephrol. 2017;32(8):1451-1456.

65. Lebensburger JD, Palabindela P, Howard TH, Feig DI, Aban I, Askenazi DJ. Prevalence of acute kidney injury during pediatric admissions for acute chest syndrome. Pediatr Nephrol. 2016;31(8):13631368 .
66. Aban I, Baddam S, Hilliard LM, Howard TH, Feig DI, Lebensburger JD. Severe anemia early in life as a risk factor for sickle-cell kidney disease. Blood. 2017;129(3):385-387.

67. Lebensburger JD, Cutter GR, Howard TH Muntner P, Feig DI. Evaluating risk factors for chronic kidney disease in pediatric patients with sickle cell anemia. Pediatr Nephrol. 2017;32(9):1565-1573.

68. Zahr RS, Rampersaud E, Kang G, et al. Children with sickle cell anemia and APOL1 genetic variants develop albuminuria early in life. Haematologica. 2019;104(9):e385 e387.

69. Wang WC, Ware RE, Miller ST, et al. Hydroxycarbamide in very young children with sickle-cell anaemia: a multicentre, randomised, controlled trial (BABY HUG). ancet. 2011:377(9778):1663-1672.

70. Alvarez O, Miller ST, Wang WC, et al. Effect of hydroxyurea treatment on renal function parameters: results from the multi-center placebo-controlled BABY HUG clinical trial for infants with sickle cell anemia. Pediatr Blood Cancer. 2012;59(4):668-674.

71. McKie KT, Hanevold CD, Hernandez C, Waller JL, Ortiz L, McKie KM. Prevalence, prevention, and treatment of microalbuminuria and proteinuria in children with sickle cell disease. J Pediatr Hematol Oncol. 2007;29(3):140-144

72. Lebensburger J, Johnson SM, Askenazi DJ, Rozario NL, Howard TH, Hilliard LM. Protective role of hemoglobin and fetal hemoglobin in early kidney disease for children with sickle cell anemia. Am J Hematol. 2011;86(5):430-432.

73. Zahr RS, Hankins JS, Kang G, et al. Hydroxyurea prevents onset and progression of albuminuria in children with sickle cell anemia. Am J Hematol. 2019;94(1):E27-E29.

74. Aygun B, Mortier NA, Smeltzer MP, Shulkin BL, Hankins JS, Ware RE. Hydroxyurea treatment decreases glomerular hyperfiltration in children with sickle cell anemia. Am J Hematol. 2013;88(2):116-119.

75. Fitzhugh CD, Wigfall DR, Ware RE Enalapril and hydroxyurea therapy for children with sickle nephropathy. Pediatr Blood Cancer. 2005;45(7):982-985

76. Desselas E, Thuret I, Kaguelidou F, et al Mortality in children with sickle cell disease in mainland France from 2000 to 2015 Haematologica. 2020;105(9):e440-443.

77. DeBaun MR, Kirkham FJ. Central nervous system complications and management in sickle cell disease. Blood. 2016;127(7):829838.

78. DeBaun MR, Armstrong FD, McKinstry RC, Ware RE, Vichinsky E, Kirkham FJ. Silent cerebral infarcts: a review on a prevalent and progressive cause of neurologic injury in sickle cell anemia. Blood. 2012;119(20):45874596

79. Kirkham FJ, Hewes DK, Prengler M, Wade A, Lane R, Evans JP. Nocturnal hypoxaemia and central-nervous-system events in sicklecell disease. Lancet. 2001;357(9269):1656 1659.

80. Miller ST, Macklin EA, Pegelow CH, et al. Silent infarction as a risk factor for over stroke in children with sickle cell anemia: a report from the Cooperative Study of Sickle Cell Disease. J Pediatr. 2001;139(3):385-390.

81. Bernaudin F, Verlhac S, Chevret $S$, et al. G6PD deficiency, absence of alpha-thalassemia, and hemolytic rate at baseline are significant independent risk factors for abnormally high cerebral velocities in patients with sickle cell anemia. Blood. 2008;112(10):4314-4317.
82. Miller ST, Milton J, Steinberg MH. G6PD deficiency and stroke in the CSSCD. Am J Hematol. 2011;86(3):331.

83. Bernaudin F, Verlhac S, Arnaud C, et al Impact of early transcranial Doppler screening and intensive therapy on cerebral vasculopathy outcome in a newborn sickle cell anemia cohort. Blood. 2011;117(4):1130 1140; quiz 1436.

84. Adams RJ, McKie VC, Hsu L, et al Prevention of a first stroke by transfusions in children with sickle cell anemia and abnormal results on transcranial Doppler ultrasonography. N Engl J Med. 1998;339(1):5-11

85. Abdullahi SU, DeBaun MR, Jordan LC, Rodeghier M, Galadanci NA. Stroke recurrence in Nigerian children with sickle cell disease: evidence for a secondary stroke prevention trial. Pediatr Neurol. 2019;95:73-78.

86. Hankins JS, Fortner GL, McCarville MB, et al. The natural history of conditional transcranial Doppler flow velocities in children with sickle cell anaemia. Br J Haematol. 2008;142(1):94-99.

87. Lee YS, Jung KH, Roh JK. Diagnosis of moyamoya disease with transcranial Dopple sonography: correlation study with magnetic resonance angiography. J Neuroimaging. 2004;14(4):319-323

88. Deane CR, Goss D, Bartram J, et al Extracranial internal carotid arterial disease in children with sickle cell anemia. Haematologica. 2010;95(8):1287-1292.

89. Bernaudin F, Verlhac S, Arnaud C, et al Chronic and acute anemia and extracrania internal carotid stenosis are risk factors for silent cerebral infarcts in sickle cell anemia. Blood. 2015;125(10):1653-1661.

90. Mirre E, Brousse V, Berteloot L, et al. Feasibility and efficacy of chronic transfusion for stroke prevention in children with sickle cell disease. Eur J Haematol. 2010;84(3):259-265

91. DeBaun MR, Gordon M, McKinstry RC, et al. Controlled trial of transfusions for silent cerebral infarcts in sickle cell anemia. $\mathrm{N}$ Eng J Med. 2014;371(8):699-710.

92. Hankins JS, Helton KJ, McCarville MB, Li CS, Wang WC, Ware RE. Preservation of spleen and brain function in children with sickle cell anemia treated with hydroxyurea. Pediatr Blood Cancer. 2008;50(2):293-297.

93. Gardner K, Suddle A, Kane P, et al. How we treat sickle hepatopathy and liver transplantation in adults. Blood. 2014.123(15).2302 2307

94. Allali S, de Montalembert M, Brousse V, et al. Hepatobiliary complications in children with sickle cell disease: a retrospective review of medical records from 616 patients. J Clin Med. 2019;8(9):1481.

95. Jitraruch S, Fitzpatrick E, Deheragoda M, et al. Autoimmune liver disease in children with sickle cell disease. I Pediatr. 2017;189:79-85

96. Goodwin EF, Partain PI, Lebensburger JD Fineberg NS, Howard TH. Elective cholecystectomy reduces morbidity of cholelithiasi in pediatric sickle cell disease. Pediatr Blood Cancer. 2017;64(1):113-120.

97. van Beers EJ, van Tuijn CF, Mac Gillavry MR, van der Giessen A, Schnog JJ, Biemond BJ. Sickle cell disease-related organ damage occurs irrespective of pain rate: implication for clinical practice. Haematologica. 2008:93(5):757-760

98. Gill HS, Lam WC. A screening strategy for the detection of sickle cell retinopathy in pediatric patients. Can J Ophthalmol. 2008;43(2):188-191

99. Mohan JS, Lip PL, Blann AD, Bareford D, Lip 
GY. The angiopoietin/Tie-2 system in proliferative sickle retinopathy: relation to vascular endothelial growth factor, its soluble receptor Flt-1 and von Willebrand factor, and to the effects of laser treatment. $\mathrm{Br} \mathrm{J}$ Ophthalmol. 2005;89(7):815-819.

100. Martin GC, Denier C, Zambrowski O, et al. Visual function in asymptomatic patients with homozygous sickle cell disease and temporal macular atrophy. JAMA Ophthalmol. 2017;135(10):1100-1105.

101. Martin GC, Albuisson E, Brousse V, de Montalembert M, Bremond-Gignac D, Robert MP. Paramacular temporal atrophy in sickle cell disease occurs early in childhood. Br J Ophthalmol. 2019;103(7):906-910.

102. Manara R, Dalla Torre A, Lucchetta M, et al.
Visual cortex changes in children with sickle cell disease and normal visual acuity: a multimodal magnetic resonance imaging study. Br J Haematol. 2021;192(1):151-157.

103. Adesina OO, Neumayr LD. Osteonecrosis in sickle cell disease: an update on risk factors, diagnosis, and management. Hematology Am Soc Hematol Educ Program. 2019;2019 (1):351-358.

104. Dalle Carbonare L, Matte A, Valenti MT, et al. Hypoxia-reperfusion affects osteogenic lineage and promotes sickle cell bone disease. Blood. 2015;126(20):2320-2328.

105. Chapelon E, Garabedian M, Brousse V, Souberbielle JC, Bresson JL, de Montalembert M. Osteopenia and vitamin $\mathrm{D}$ deficiency in children with sickle cell dis- ease. Eur J Haematol. 2009:83(6):572-578.

106. Milner PF, Kraus AP, Sebes JI, et al. Sickle cell disease as a cause of osteonecrosis of the femoral head. $N$ Engl J Med. 1991;325(21):1476-1481.

107. Mallet C, Abitan A, Vidal C, et al. Management of osteonecrosis of the femoral head in children with sickle cell disease: results of conservative and operative treatments at skeletal maturity. J Child Orthop. 2018;12(1):47-54.

108. de Montalembert M, Ferster A, Colombatti R, Rees DC, Gulbis B. ENERCA clinical recommendations for disease management and prevention of complications of sickle cell disease in children. Am J Hematol. 2011;86 (1):72-75 